\title{
Impact of aperture separation on wind-driven single-sided natural ventilation
}

\author{
N. C. Daish ${ }^{(\dagger) a}$, G. Carrilho da Graça ${ }^{\mathrm{a}, \mathrm{b}}$, P. F. Linden ${ }^{\mathrm{a}, \mathrm{c}}$ and D. Banks ${ }^{\mathrm{d}}$ \\ ${ }^{a}$ Department of Mechanical and Aerospace Engineering, University of California, San Diego, 9500 Gilman \\ Drive, La Jolla, CA 92093, USA

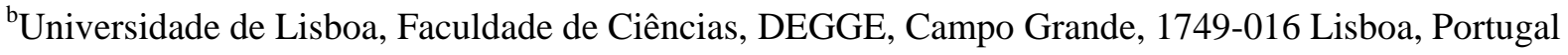 \\ ${ }^{\mathrm{c}}$ Department of Applied Mathematics and Theoretical Physics, Centre for Mathematical Sciences, \\ Wilberforce Road, Cambridge, CB3 0WA, UK \\ ${ }^{\mathrm{d}}$ CPP Wind Engineering, Inc., 2400 Midpoint Drive, Suite 190, Fort Collins, CO 80525, USA
}

\begin{abstract}
This paper presents a study of the impact of horizontal aperture separation in single-sided ventilation flows with two apertures (SS2). The study is based on wind tunnel measurements and dimensional analysis. The results show that the SS2 ventilation flow rate, scaled with incoming wind velocity and aperture area, depends on the incoming wind angle relative to the aperture façade, $\theta$, and on the aperture separation scaled by building width, $s^{\prime}$. For most wind angles, the ventilation flow increases as the square-root of $s^{\prime}$. This study also identified a novel flow driving mechanism - vortex shedding: when the ventilation openings are on the leeward side of the building and the wind is nearly head-on, the flow is driven by a pumping mechanism due to vortex shedding.
\end{abstract}

Keywords: wind-driven, natural ventilation, single-sided, wind tunnel

${ }^{(\dagger)}$ Corresponding author

Present address as (c) above; email ncd1@ cam.ac.uk; phone +44 1223 764043/+44 7879887776 


\section{Introduction}

Reducing energy usage in the building stock is a desirable goal from the point of view of both lower running costs for owners or occupiers and fewer emissions of pollutants and greenhouse gases from fossil fuel-based energy generation. Natural ventilation can be an important potential source of energy savings for space conditioning (cooling and ventilation), particularly in the commercial building sector, either alone or supplemented with mechanical conditioning in a hybrid approach.

The primary agents harnessed in natural ventilation are two-fold: the wind, impacting on the openings in the exterior of the building; and temperature differences, between the exterior and interior caused by internal sensible heat gains. In typical natural ventilation configurations one or more open windows ventilate the internal space. The case of two openings is the simplest multi-opening situation, and leads to four possible airflow regimes, depending on the relative opening position

- Single-sided ventilation, SS

- Corner ventilation, $\mathrm{CR}$

- Cross-ventilation, $\mathrm{CV}$

- Displacement ventilation, DV

in which the two openings are in the same, adjacent, or opposite external façades, or at different heights, respectively (Figure 1).
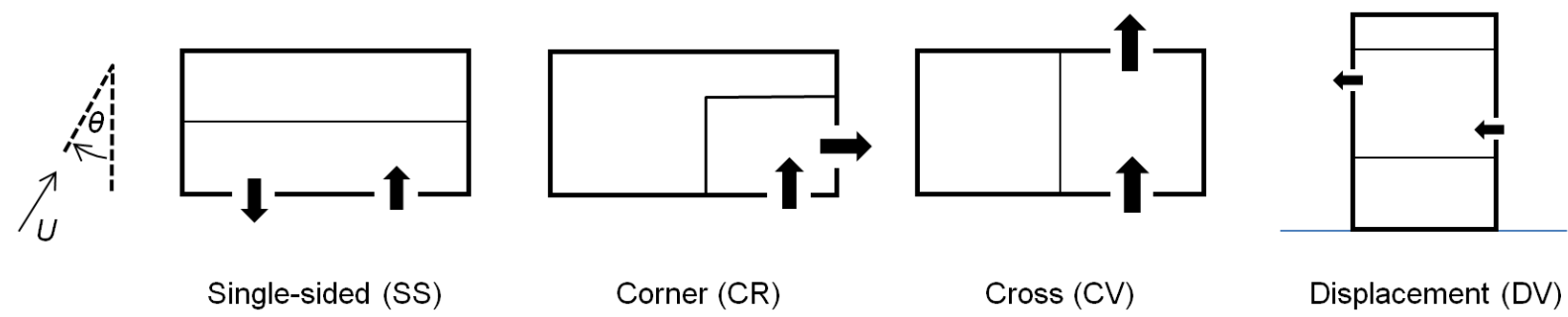

Figure 1: Ventilation regimes with 2 apertures (DV shown in elevation, others in plan view). 
In the first three flow regimes, wind-generated flow will be dominant unless the wind is light enough and/or the temperature differences are sufficiently large. This paper will focus on wind-driven flows and, therefore, will not discuss displacement ventilation or interactions between buoyancy and wind.

Many studies of natural ventilation focus on cross-ventilation because of its potential to achieve large flow rates that maximise free-cooling capacity $[1,2,3]$. Unfortunately, the large cooling potential of CV is difficult to realise because in most cases the high flow rates are incompatible with office tasks and may result in draft-induced discomfort (particularly in the jet region of the flow [4]). Further, CV requires that the room must have opposing external walls, a characteristic that most rooms in the perimeter of a building do not have. The corner ventilation case is fairly similar in character to cross-ventilation $[5,6]$ and furthermore is relevant to only a relatively small percentage of offices. On the other hand, in many perimeter office spaces, SS systems that induce lower, more manageable, ventilation rates can be a good option. Perimeter spaces often have limited room depth and therefore, for at least some parts of the year, the smaller cooling capacity of SS may be sufficient [7].

Single-sided ventilation systems can be divided into two types: single-opening (SS1) and multiple-opening (SSn). In terms of the physical picture of single-sided ventilation, there is a fundamental divide between one opening and more than one opening, since in the former case the external air entering and the internal air being removed must both pass through the same opening, while in the latter case there can be a clearer division between inlet and outlet openings. This difference means the single-opening case is somewhat limited in its ability to ventilate a room, whereas a room with two or more openings on the same façade can give a substantial supply of fresh air under many circumstances. Hence SS1 systems form the typical option for small offices, while systems with multiple openings in distinct zones of the façade are the choice for large rooms.

The SS1 case has been much studied $[8,9,10,11]$ and explained in terms of unsteady static pressure variations across the opening, a growing shear layer generated by the flow along the building façade, or a combination of both. Recently, Ai and Mak [12] measured instantaneous flow rates in a single-room small building in a boundary layer wind tunnel and concluded that the fluctuating part of the flow contributed between 15 and $64 \%$ to the ventilation rate (depending on wind direction). Simple scalings for the SS1 
ventilation rate were proposed and validated by Warren and Parkins [8]. This pioneer study was also one of the first to address the effect of window geometry. Subsequently several authors, including Heiselberg et al. [13], Caciolo et al. [14] and Wang et al. [15], have worked on this important effect, which is difficult to model accurately in typical small-scale wind tunnel studies.

The two-aperture single-sided case (SS2), on the other hand, is potentially a common practical situation and yet is not well-represented in the literature. Warren and Parkins [8] measured single-sided ventilation driven by multiple openings in a single façade in a full-scale building, but the study was inconclusive and did not result in a model. Cóstola et al. [16] showed that wind-generated pressure variations along the façade can be significant with, therefore, the potential to generate useful flow rates. Teppner et al. [17] tested a 3-storey section of a 10-storey building $(14 \mathrm{~m} \times 21 \mathrm{~m} \times 30 \mathrm{~m})$ at $1: 25$ scale in an aerodynamic wind tunnel. This study revealed significant pressure variations $\Delta \square$ along the façade at a given height: $\Delta \square /\left(1 / 2 \square \square^{2}\right) \sim 0.5$, where $U$ is the approach flow velocity scale. Chu et al. [18] studied a small single-storey building with two openings in the same façade and proposed a simple model to predict ventilation flow rates. The study used openings a fixed distance apart and, therefore, the proposed model does not include aperture separation effects. The model distinguishes two ranges for the incoming wind angle $\theta$ where different mechanisms drive the flow: for wind directions in the range $22.5-45^{\circ}$ region the flow is driven by pressure difference between the two openings, while for the remaining angles the flow is driven by pressure fluctuations and (for $90^{\circ}$ wind) by shear.

SS2 flows are primarily the result of differences in static pressure between the openings: inflow occurs at the openings with higher pressure and outflow occurs at the openings with the lower pressure. This pressure difference is driven by the external flow and comprises a combination of steady and unsteady components whose relative contributions depend primarily on wind angle and aperture separation.

Turbulent external flow leads to unsteadiness in the pressure field, which means the pressure difference changes with time in both magnitude and sign. This leads to a contribution to the ventilation rate provided the frequency is low enough: if the pressure difference fluctuates too rapidly then it drives fluid in and out again before it has been able to mix with the internal air. The unsteady contribution is present in all cases but is particularly important when the mean pressure difference is approximately zero. One extreme but 
interesting manifestation of this unsteady contribution occurs when the openings are on the leeward side of the building. In this case, discussed in Section 2.1, the flow is driven primarily by the low-frequency periodic effect associated with Strouhal vortex shedding [19].

The objective of this paper is to examine in more detail the effect of aperture separation in SS2 flows and to use a combination of wind tunnel measurements and dimensional analysis to develop simple formulae to predict the ventilation rate in terms of basic parameters describing both the incoming wind and the building. These formulae should be simple enough to allow their straightforward integration in simplified simulation tools such as EnergyPlus [20].

The rest of this paper proceeds as follows. Section 1 presents the wind tunnel experimental set-up. Section 2 gives an overview of the results used in the subsequent modelling work - the characteristics of the pressure difference between the two apertures and the associated ventilation rates - and concludes by deriving a formula connecting the measured ventilation rate with the magnitude and characteristics of the driving pressure difference at the two openings. Section 3 then takes this a stage further by proposing a simple expression for the driving pressure difference in terms of the characteristics of the incoming wind and the opening separation scaled by the characteristic length of the building façade, which can then be combined with the previous result to relate the ventilation rate to the parameters describing the set-up. Thus the paper offers two levels of use, depending on the type of data available: when pressure (difference) data are available, the results in Section 2 may be used; while if only basic set-up parameters are known, the formulation in Section 3 is appropriate. The latter offers a more accessible model, but with increased uncertainty in some circumstances due to additional assumptions. 


\section{Wind tunnel measurements}

The wind tunnel used in this study is located in Fort Collins, Colorado, USA and operated by CPP Wind Engineering, Inc. The closed circuit boundary layer wind tunnel has a $3 \mathrm{~m} \times 2.7 \mathrm{~m}$ working cross section.

The test set-up comprised two rectangular building models each containing a single room occupying an entire floor (Figure 2).

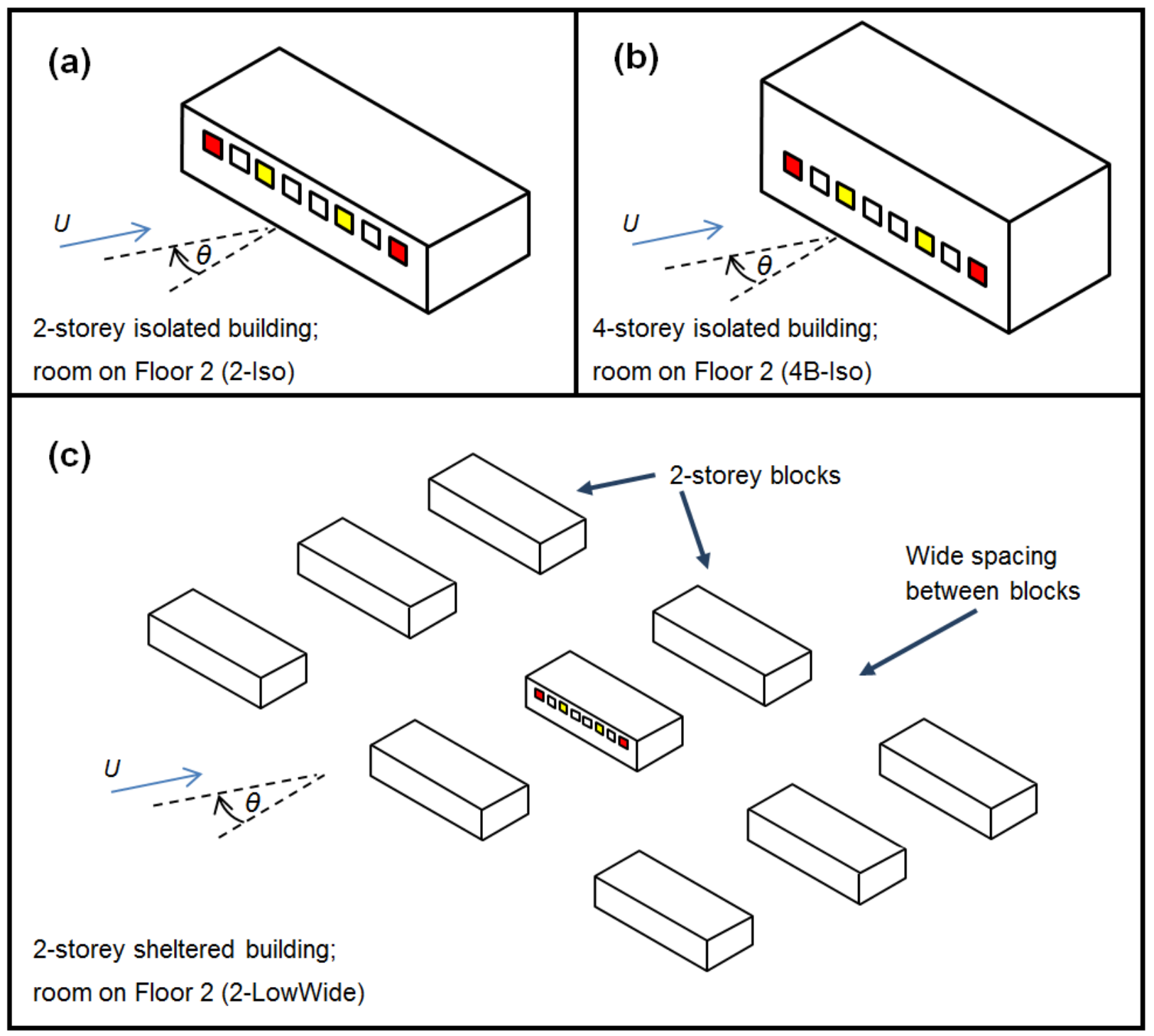

Figure 2: Three building/room configurations analysed: S1:S8 openings shaded red, S3:S6 openings shaded yellow.

The building models were either isolated or, in the case of the 2-storey building, surrounded by a set of similar 2-storey blocks, representing a low-density urban environment. The buildings were modelled at 1:70 
scale, and equipped with pressure taps, tracer injection ports and two concentration receptor locations

(Figure 3). To simulate variations in incoming wind direction, the models were placed on a turntable and measurements were made for a set of equally-spaced wind directions.

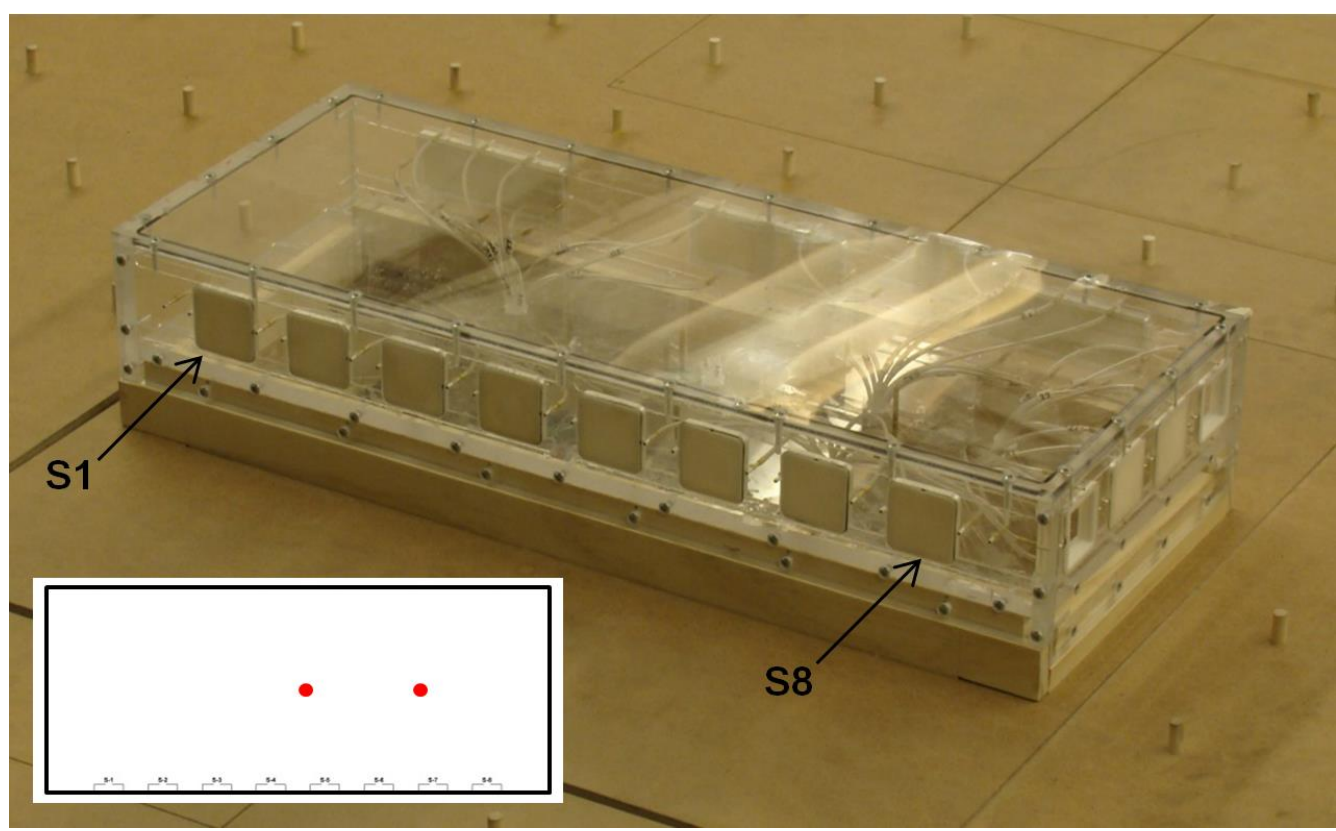

Figure 3: 2-storey model building. Apertures are labelled S1 through S8. Inset shows position of internal concentration sampling points (red dots).

Two types of run were carried out:

- Closed box runs, in which all apertures were sealed and surface pressure was measured around building. Seventeen wind angles $\left(0^{\circ}, 11.25^{\circ}, 22.5^{\circ}, \ldots, 180^{\circ}\right)$ were investigated.

- Ventilation runs, in which two apertures were open and surface pressure and concentration decay were measured. Nine wind angles $\left(0^{\circ}, 22.5^{\circ}, 45^{\circ}, \ldots, 180^{\circ}\right)$ were investigated.

The details are summarised in Table 1.

For each building configuration and incoming wind direction two opening separations were tested: wide (denoted 'S1:S8' and marked in red in Figure 2) and narrow (denoted 'S3:S6' and marked in yellow in Figure 2). The combination of three building configurations, two opening arrangements and a range of wind directions resulted in a total of $3 \times 2 \times 17=102$ closed box runs and $3 \times 2 \times 9=54$ ventilation runs. 
Table 1: Summary of test parameters

\begin{tabular}{|l|l|}
\hline \multicolumn{1}{|c|}{ Feature } & \multicolumn{1}{c|}{ Options } \\
\hline Configurations & $\begin{array}{l}\text { (1) 2-storey isolated: } 47.5 \mathrm{~cm}(\mathrm{~W}) \times 19.3 \mathrm{~cm}(\mathrm{D}) \times 9.9 \mathrm{~cm}(\mathrm{H}) \\
\text { (2) 4-storey isolated: } 47.5 \mathrm{~cm}(\mathrm{~W}) \times 19.3 \mathrm{~cm}(\mathrm{D}) \times 18.6 \mathrm{~cm}(\mathrm{H}) \\
\text { (3) 2-storey sheltered: as (1) but centred in grid of 2-storey } \\
\text { blocks, horizontal separation } 50.8 \mathrm{~cm} \text { in both directions } \\
\text { Maximum blockage ratio: } 0.63 \%, 1.18 \% \text { and } 3.6 \%, \text { respectively } \\
\text { In each case, room dimensions were } 45.9 \mathrm{~cm} \times 17.7 \mathrm{~cm} \times 5.0 \mathrm{~cm}\end{array}$ \\
\hline Openings & $\begin{array}{l}\text { Opening dimensions: } 2.54 \mathrm{~cm} \times 2.54 \mathrm{~cm} . \\
(1) \text { Wide separation ('S1:S8'): } 35.4 \mathrm{~cm} \text { between centres } \\
(2) \text { Narrow separation ('S3:S6'): } 15.1 \mathrm{~cm} \text { between centres }\end{array}$ \\
\hline Wind angles & $\begin{array}{l}\theta=0^{\circ}, 11.25^{\circ}, 22.5^{\circ}, \ldots, 180^{\circ}(\text { closed-box runs) } \\
\theta=0^{\circ}, 22.5^{\circ}, 45^{\circ}, \ldots, 180^{\circ} \text { (ventilation runs) }\end{array}$ \\
\hline Data capture & $\begin{array}{l}1 \mathrm{kHz} \text { sampling rate for } 90 \mathrm{~s} \text { (closed-box runs) or } 250 \mathrm{~Hz} \text { for } 80 \mathrm{~s} \\
(\text { ventilation runs) }\end{array}$ \\
\hline
\end{tabular}

The tunnel uses spires and a trip at the leading edge of the test section to initiate the development of a simulated atmospheric boundary layer. The long development region between the spires and the test building is filled with roughness elements in a pattern experimentally set to develop the appropriate approach wind profile. This set-up creates the logarithmic incoming wind profile [21] shown on the left-hand side of Figure 4. Similarity requirements were met in accordance with the EPA fluid modelling guidelines [22] and with Cermak $[23,24,25]$.
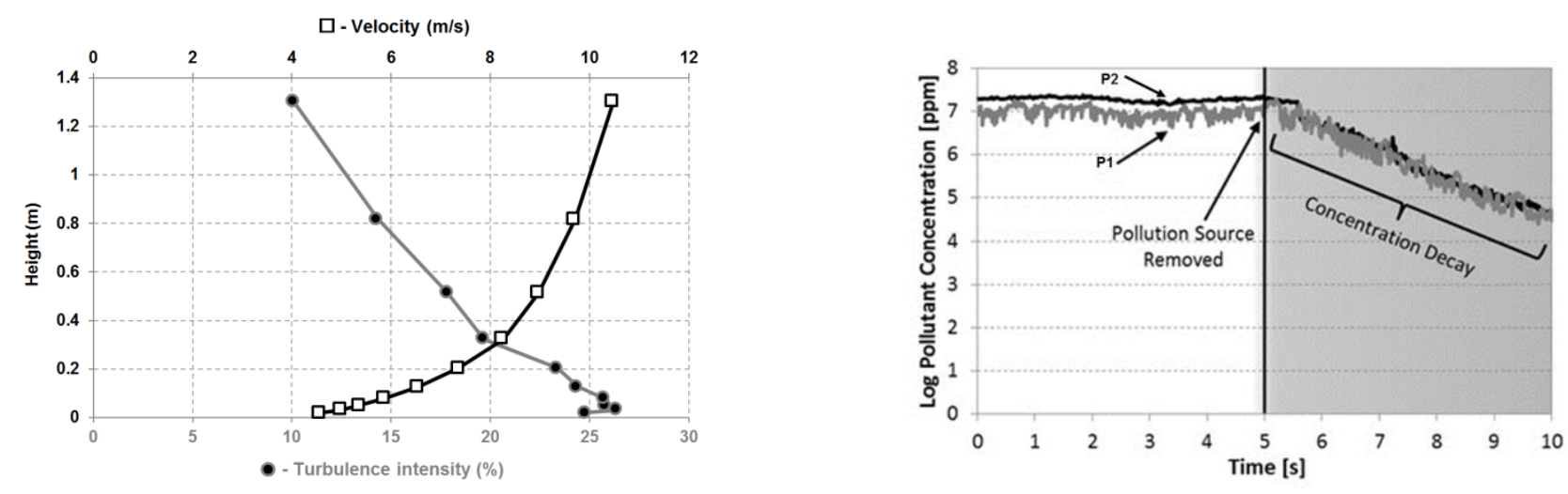

Figure 4: Left: wind tunnel velocity and turbulence intensity profiles. Right: pollution concentration decays.

Time-resolved pressure measurements (sampled at $1000 \mathrm{~Hz}$ ) were obtained by means of flush surface pressure mounts located on building walls and around building openings. To obtain an estimate of the 
ventilation rate, time series concentration data (sampled at $250 \mathrm{~Hz}$ ) were collected at receptor locations mounted at approximately mid-room height through the test building floor (Figure 3). The building was flushed with a fixed concentration of ethane-in-nitrogen gas that was mixed using mass flow controllers. A solenoid valve was used to control the flow of tracer gas into the test building through ports in the floor. The building was purged for a pre-set time sufficient to allow the concentration to reach a near-steady state. Depending upon the test iteration, a range of 2500ppm-5000ppm ethane tracer was achieved. The right-hand side of Figure 4 shows the concentration in one of the measurements: the rate of concentration decay is used to infer the ventilation rate. During the filling phase, the concentration varies between the two measurement points (when the non-buoyant pollutant source is active), but once the source is removed there is increased homogeneity, leading to a difference in the decay rate of less than $10 \%$ between the two points for most incoming wind directions. Flow visualization was conducted on particular runs of interest in which a mixture of pharmaceutical mineral oil and UV dye was used to charge the test building. The smoke wand was then removed and the building allowed to be ventilated naturally while being recorded from above. A lower velocity tunnel speed was required to allow the video camera to capture the flow structure. 


\section{Analysis of SS2 flows}

This section presents a detailed analysis of SS2 flows, beginning with a discussion of the dominant flow pattern/driving mechanisms followed by an analysis of the variation of flow rate with incoming wind angle. This section concludes with a quantitative expression of the relation between flow and pressure.

\subsection{Overview of SS2 flow patterns}

Analysis of the flows observed in these (and earlier [5]) wind tunnel experiments revealed ranges of the incoming wind angle $\theta$ dominated by particular flow driving mechanisms:

- $0^{\circ}-60^{\circ}$ : nearly head-on wind results in an unstable flow with inflow and outflow through each of the openings alternating over timescales short compared with the Strouhal frequency (see below) and no clear periodic behaviour.

- $67.5^{\circ}$ : for this angle the external flow is attached to the building façade and the ventilation is driven by shear (similar to single opening flows [10]).

- $90^{\circ}-170^{\circ}$ : flow driven by stable static pressure difference, predominantly through the downstream opening

- 175-180': oscillating "pumping" flow driven by Strouhal [19] vortex shedding with clear quasiperiodic behaviour.

Figure 5 highlights three particular cases of importance.

(a) When $\theta=0^{\circ}$ the wind is head-on to the façade containing the openings. Inflow alternates rapidly between the two windows. This is typical of wind directions up to around $90^{\circ}$.

(b) When $\theta=90^{\circ}$, the incoming wind is parallel to the openings façade. The flow is predominantly in through the downstream aperture, with occasional inflow at the upstream opening. This is typical of wind directions from around $90^{\circ}$ to almost $180^{\circ}$, with the unidirectionality becoming stronger for intermediate angles but then diminishing. 
(c) The case $\theta=180^{\circ}$, where the wind is head-on to the façade opposite that containing the openings, shows markedly (quasi-)periodic inflow, in which the flow spends relatively long periods (compared with (a)) entering through first one opening and then the other. This is likely to occur also when the wind direction is close to $180^{\circ}$.
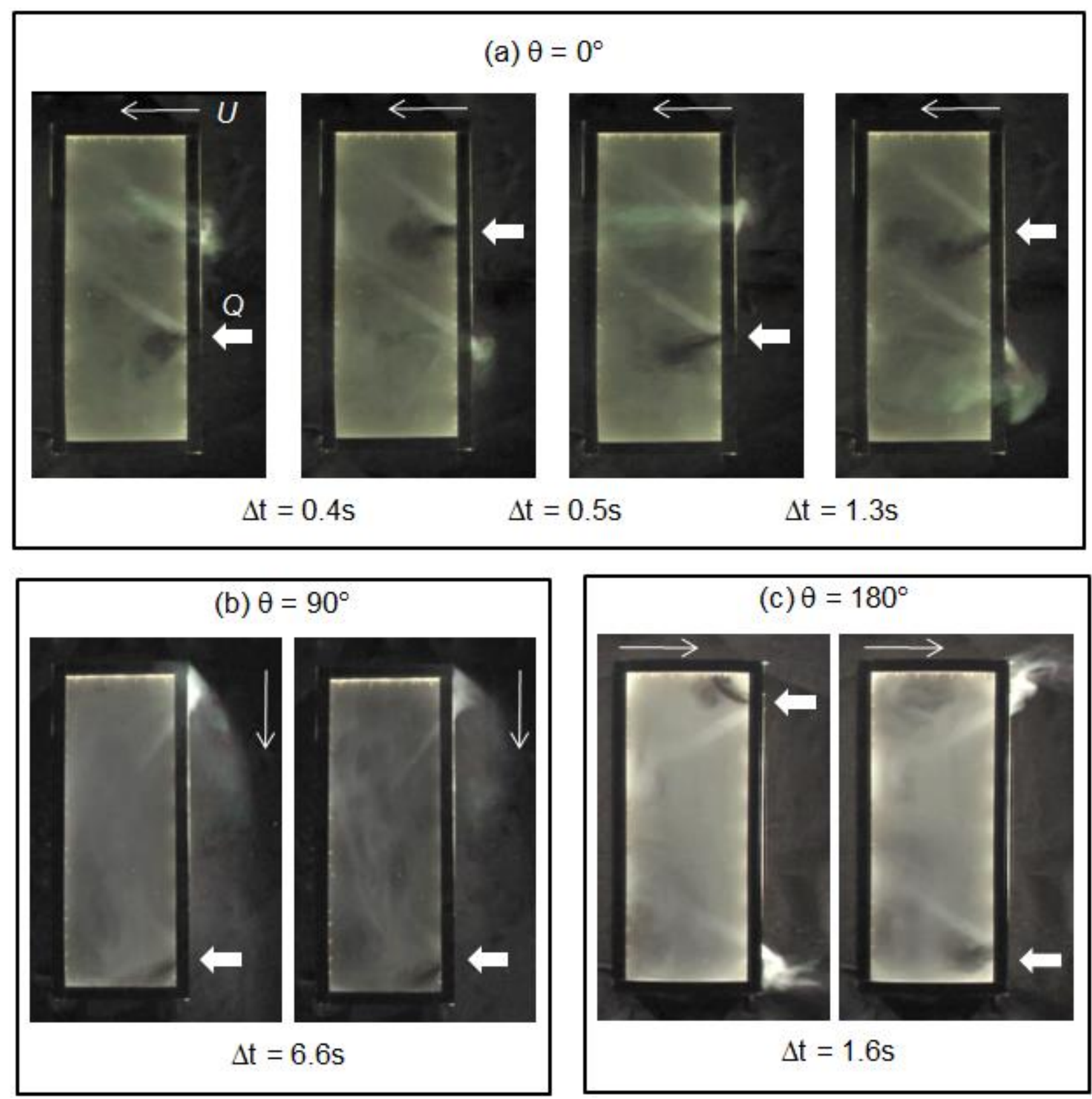

Figure 5: Snapshots of flow for three wind angles: (a) $0^{\circ}$, (b) $90^{\circ}$ and (c) $180^{\circ}$. Values of $\Delta t$ indicate time between frames for a given angle. The vector $U$ gives the wind direction, while $Q$ indicates the instantaneous inflow opening. 
The oscillating "pumping" flow mechanism is unique in that it displays a clear quasi-periodic behaviour that is characteristic of vortex shedding at the back of bluff bodies. This ventilation flow oscillates with the Strouhal frequency, $\square$, or period $\square$, which is defined via

$$
\square \square=\square \square / \square=\square / \square \square
$$

where $L$ is a characteristic length scale of the body and $U$ the velocity scale. The value of $S t$ depends on the Reynolds number and the body geometry, but is typically in the range 0.1-0.15 [25].

Figure 6 shows a set of snapshots of a pumping ventilation flow. For the case shown, the time sequence for the appearance of smoke at the openings in the visualisation video suggests a mean period of $T=3.3 \mathrm{~s}$, giving a Strouhal number of around 0.11 (based on length and velocity scales equal to the building width, $W_{\mathrm{B}}$, and the incoming velocity at building height, $U_{\mathrm{a}}\left(H_{\mathrm{B}}\right)$, respectively). This is consistent with other studies [25]. Pumping flow is also likely to occur for incoming wind angles close to $180^{\circ}$, i.e. when the wind is not perfectly normal to the windward side.
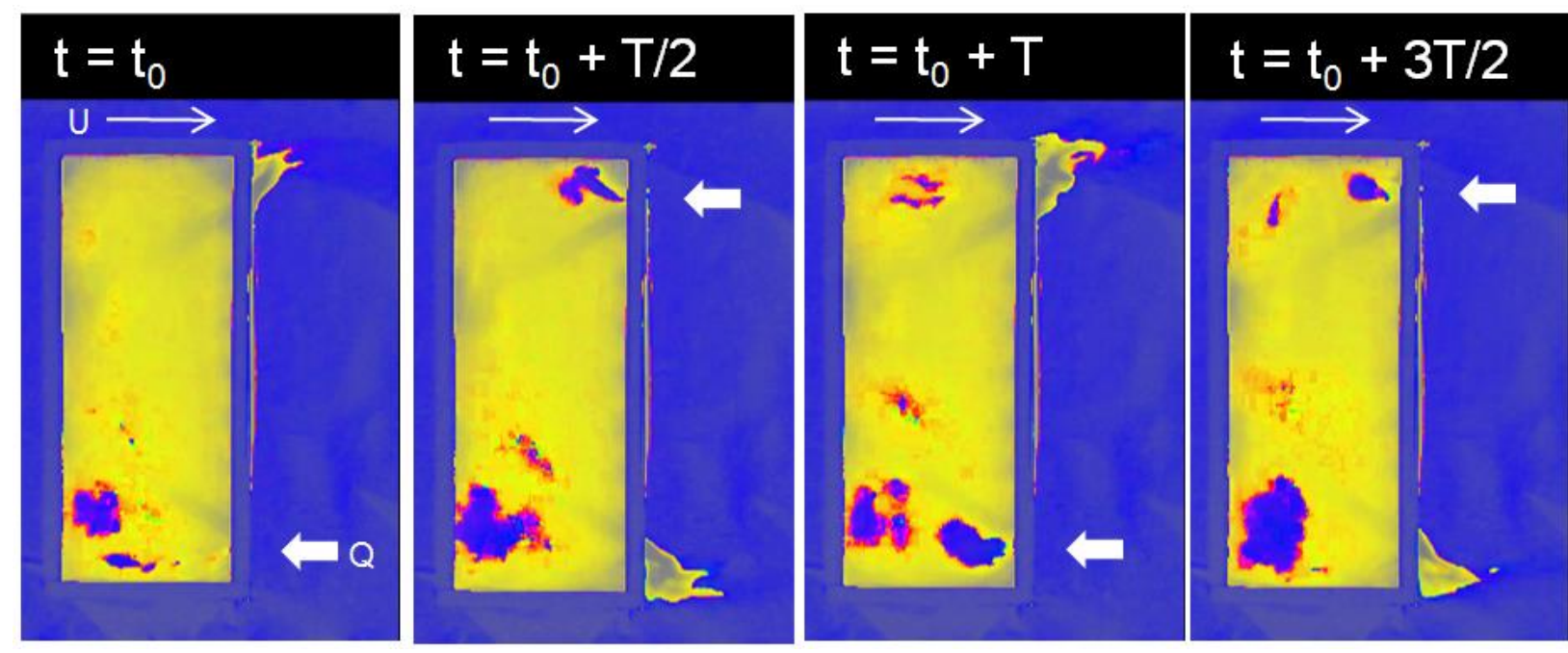

Figure 6: Detailed look at pumping flow (driven by Strouhal frequency vortex shedding). False colour has been used to enhance visualisation of clean air (blue) entering smoke-filled space (yellow). The four snapshots are equally separated in time by half the mean pumping period $\mathrm{T}$.

\subsection{Variation of SS2 flow rate}

Traditionally [8], the SS flow rate $Q$ is analysed in terms of a non-dimensional ventilation rate $\square^{\prime}$, defined by 


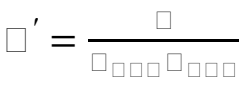

where $A_{\text {ref }}$ and $U_{\text {ref }}$ are characteristic opening area and velocity scales, respectively.

We take the area scale to be the effective opening area, $A_{\text {eff }}$, defined by

$$
\square_{\square \square \square}=\frac{\square_{1} \square_{2}}{\left(\square_{1}^{2}+\square_{2}^{2}\right)^{1 / 2}}
$$

in which $A_{1}$ and $A_{2}$ are the areas of the individual openings. Note that when $A_{1}=A_{2}=A$, then $A_{\text {eff }}=A / \sqrt{ } 2$. This area scale arises naturally from a simple pressure balance calculation of the ventilation rate [26]. We take the velocity scale $U_{\text {ref }}$ to be the ambient flow $U_{\mathrm{a}}(z)$ at a reference height, $z_{\text {ref }}$

$$
\square_{\square \square \square}=\square_{\square}\left(\square_{\square \square \square}\right)
$$

with $z_{\text {ref }}=10 \mathrm{~m}$.

We wish to relate the flow rate to the pressure difference, $\Delta \square=\square_{1}-\square_{2}$. The mean and unsteady components of $\Delta \square$ are characterised using the time-average $\overline{\Delta \square}$ and standard deviation $\square_{\Delta \square}$, respectively. Further, we express these in the form of pressure coefficients

$$
\begin{gathered}
\Delta \square_{\square}=\frac{\overline{\Delta \square}}{\frac{1}{2} \square_{\square \square \square \square^{2}}} \\
\square_{\Delta \square \square}=\frac{\square_{\Delta \square}}{\frac{1}{2} \square \square \square \square \square \square}{ }^{2}
\end{gathered}
$$

where $\rho_{\mathrm{a}}$ is the ambient air density. We henceforth refer to these coefficients as the mean (or steady) and fluctuating (or unsteady) pressure differences, respectively.

Consider the variation of the non-dimensional flow rate and pressures for one example, namely the twostorey building in isolated surroundings (Figure 2(a)). Figure 7 shows (a) the non-dimensional ventilation rate $\square$ ' as a function of incoming wind angle $\theta$ for the two opening separations analysed in this study, (b) the corresponding mean pressure difference coefficients, $\Delta \square_{\square}$, and (c) the unsteady pressure difference

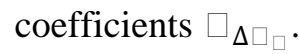

Analysis of the three plots shows: 
(i) There is a clear correlation between (a) $\square$ 'and (b) $\Delta \square_{\square}$. The maximum flow rate occurs when the pressure difference magnitude is greatest, and the minimum flow rate when the mean pressure difference is zero.
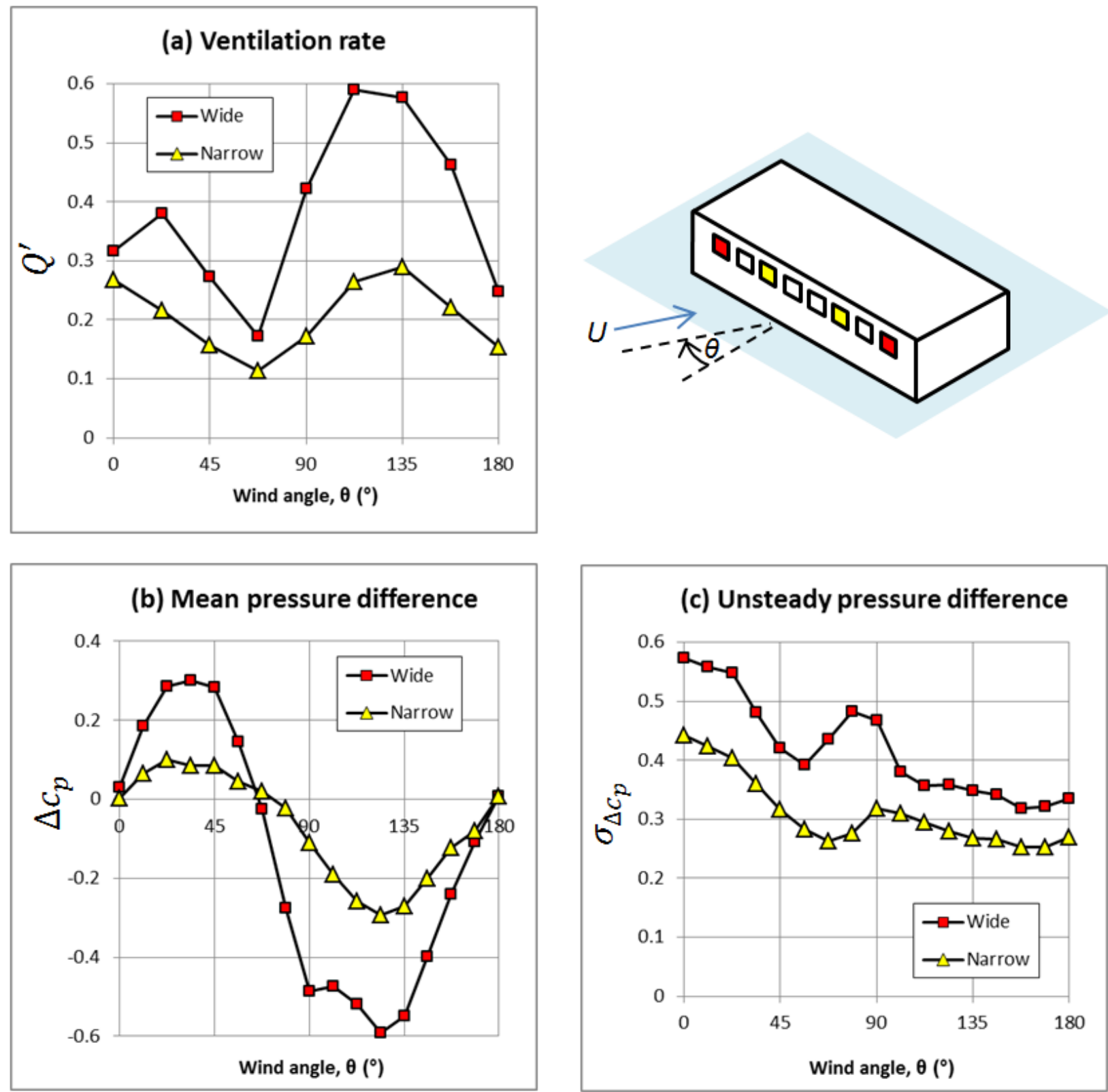

Figure 7: Non-dimensional flow rate and mean and fluctuating parts of pressure difference coefficients for 2storey isolated building.

(ii) There is a non-zero ventilation rate at all angles, even when the mean pressure difference is zero.

The minimum flow rate is still significant - about $30-40 \%$ of the maximum - suggesting that other effects besides the static mean pressure difference $\Delta \square_{\square}$ contribute to the ventilation flow rate. There 
is a substantial flow rate when the wind is head-on $(\theta=0)$, despite the negligible mean pressure difference. Unsteady effects must therefore be the major contributor to flow rate under these conditions. Note that the unsteady part is weakest for leeward locations, i.e. in the building wake, and the greatest level of unsteadiness is experienced on the side exposed to the wind, with a maximum at $\theta=0$.

(iii) Clearly, opening separation has an important effect on the flow rate; for the cases in the graphs there is an approximately linear increase in flow rate with aperture separation. The general trend with wind angle is similar for both separations.

(iv) The minimum flow rate occurs at $\square=\square_{0} \simeq 67.5^{\circ}$ This angle is likely to be dependent on the building geometry. Note that $\square_{0} \neq 90^{\circ}$ : there is a significant ventilation flow when the approaching wind is parallel to the façade with the openings.

Note that the unsteady pressure is based on the standard deviation of the pressure which, by definition, includes all frequencies of fluctuations. As noted earlier, the higher frequencies will not contribute to the ventilation, so the effect of a low-pass filter applied to the pressure difference was investigated, in which only the frequencies low enough to allow fluid to penetrate significantly into the room are retained. The chosen threshold frequency $\square_{\square}$ is low enough that the fluid penetrates at least a distance equal to the room depth in one period. In our case this leads to the criterion $\square_{\square} \lesssim 30 \sqrt{ } \Delta \square_{\square}$. It was found that the effect of eliminating the higher frequencies on the curves shown in Figure 7(c) was to leave their shape essentially unchanged but reduce the values by around $40 \%$. Thus we expect the use of filtered data rather than unfiltered data would be simply to change the coefficients in the correlations discussed in Section 2.3 (compared with using unfiltered data). Hence at this level of approximation it is acceptable and more convenient to leave the data unfiltered and use the standard deviation.

Note also that the pressure coefficients in (b) and (c) were calculated from the closed box pressure measurements (Section 1), rather than those made simultaneously in the given ventilation run, for three main reasons: (i) pressure data for actual buildings are likely to be obtained for a closed envelope, rather than with simultaneous ventilation measurements; (ii) the presence of an opening will have a small effect on the pressure; and (iii) the closed box measurements were taken at twice as many wind angles as in the equivalent 
ventilation run and at higher sampling rate, and hence gave more detailed data for analysis in the subsequent model development.

To summarise, the analysis suggests that the mean static pressure difference has a strong correlation with the flow rate, but cannot explain all the features of the dependence on incoming wind angle, in particular the significant flow values at $0^{\circ}$ and $180^{\circ}$ (for which $\Delta \square_{\square} \sim 0$ ). In the next section we investigate quantitatively the relation between flow and pressure.

\subsection{Relation between flow and pressure}

As discussed above, the experimental data include a set of ventilation rates and static pressure measurements. From basic energy conservation principles (Bernoulli equation), we expect the following relation between non-dimensional flow and pressure

$$
\square_{\square \square \square \square}^{\prime}=\left(\square_{\square}\left|\Delta \square_{\square}\right|+\square_{\square} \square_{\Delta \square_{\square}}\right)^{1 / 2}
$$

where $\Delta \square_{\square}$ and $\square_{\Delta \square_{\square}}$ were defined in Equations (5) and (6), $\square^{\prime}{ }_{\square \square \square}$ is the correlated/predicted nondimensional flow rate and $a_{\mathrm{p}}, a_{\sigma}$ are the correlation constants.

The objective is to use the observed values of $\Delta \square_{\square}$ and $\square_{\Delta \square \square}$ for each of a set of $N$ cases - combinations of building configuration, aperture separation and wind direction - and choose the values of $a_{\mathrm{p}}, a_{\sigma}$ that provide the best match with the corresponding $N$ observed flow rates $\square_{\square \square \square}^{\prime}$ : the optimum was defined as the combination $\left(a_{\mathrm{p}}, a_{\sigma}\right)$ giving the largest value of the Pearson correlation coefficient $r$.

As noted earlier, the flow rate data to be used in this process are taken from the ventilation runs and the pressure data from the closed box runs. The number of cases $N=54$ and 102, respectively. In order to be able to use the full set of closed box pressure data, and therefore take $N=102$, linear interpolation was employed to obtain $\square_{\square \square \square}^{\prime}$ for wind directions not tested directly.

The correlation constants were varied systematically over ranges based on initial exploratory comparisons. The optimal choice of correlation was found to be $a_{\mathrm{p}}=0.32, a_{\sigma}=0.09$ (giving a maximal value of $r=0.82$ ), i.e. 


$$
\square_{\square \square \square \square}^{\prime}=\left(0.32\left|\Delta \square_{\square}\right|+0.09 \square_{\Delta \square \square}\right)^{1 / 2}
$$

The coefficients for the pressure difference terms are thus of comparable magnitude (although the static component is dominant), and both steady and unsteady pressure variations make important contributions to the ventilation.

Figure 8 shows a scatter plot of observed values versus predictions from the correlation (8). The data points have been split into three groups, corresponding to the three building configurations. Overall, the representation of the experimental data across the cases is good; this is encouraging in view of the range of conditions treated together, and both supports the tenet that pressure is the principal driver for the flow and strengthens the argument for the proposed dependence of the flow rate on the pressure difference. However, it is clear that the overall correlation (8) works best for the 2-storey isolated building (left) but least well for the 2 -storey sheltered building (right), which contributes most of the points outside the $\pm 30 \%$ error bounds across the three cases. Accordingly, the correlation should be applied with caution to this last scenario.
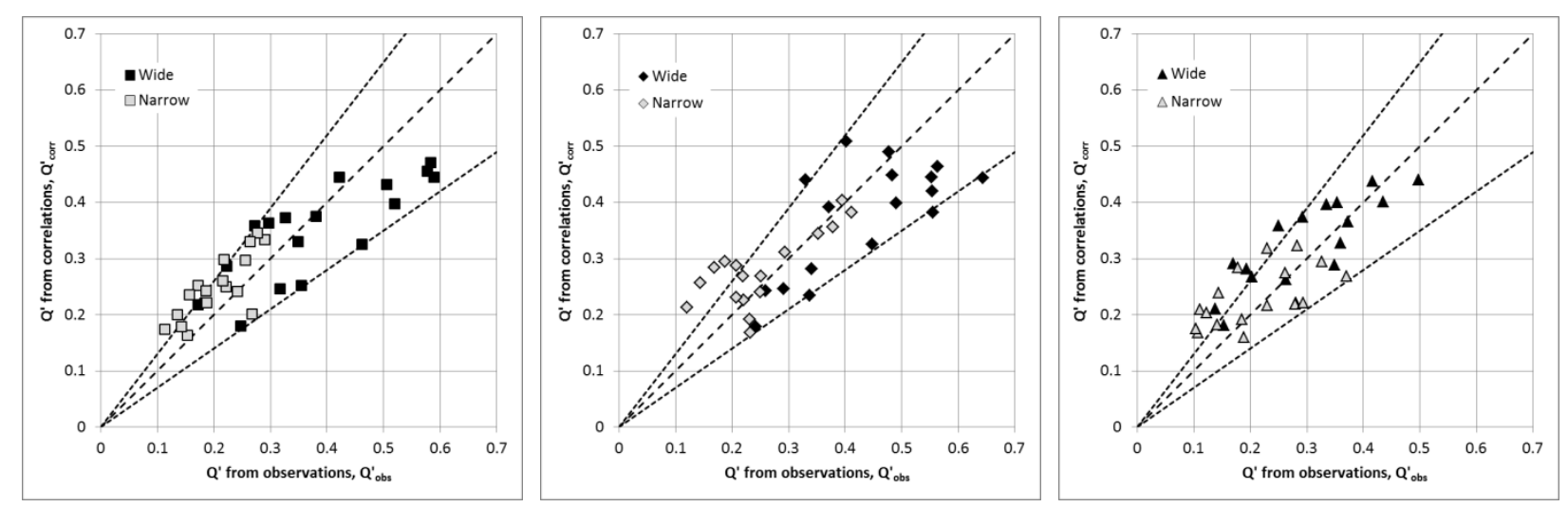

Figure 8: Comparison of pressure-based ventilation rate formula (8) with data.

The three charts plot subsets of the data corresponding to the 2-storey isolated (left), 4-storey isolated (centre) and 2-storey sheltered (right) buildings. In each case, results for the two aperture separations are distinguished and the upper and lower dashed lines indicate $\pm 30 \%$ errors.

It is interesting to consider sub-groups of the entire pool, such as the 6 sets of cases for a given aperture separation and building configuration but all 17 wind directions, and find $\left(a_{\mathrm{p}}, a_{\sigma}\right)$ for each sub-group, i.e. the values giving the best fit for that sub-group over all 17 wind directions. Figure 9 plots the coefficient pairs for each case, together with the aggregated case $(0.32,0.09)$. 


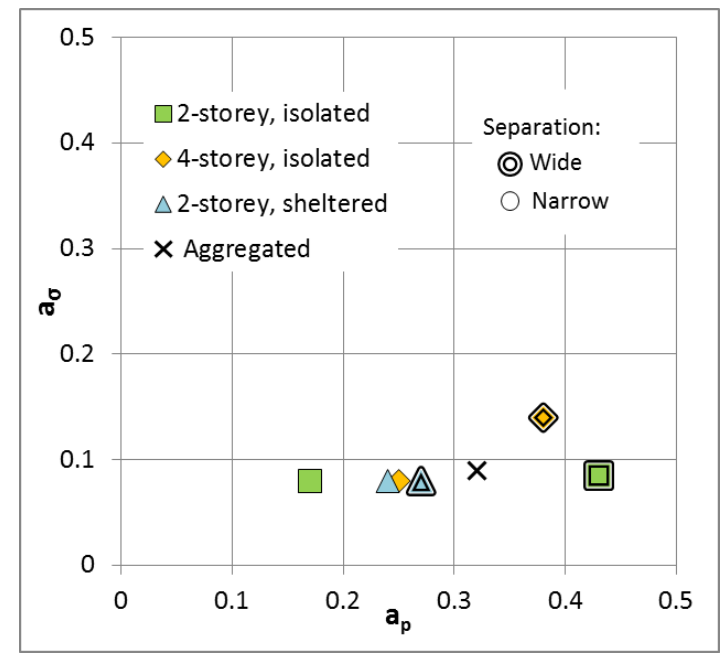

Figure 9: Correlation coefficients calculated for building sub-groups.

Note the dominant effect is that of aperture separation for isolated buildings; while the effect of separation is reduced for the sheltered building, presumably because the flow is more disordered in this case, and so the systematic variation of pressure difference with separation is subordinated. This is also reflected in the graphs of Figure 8, where the points for the isolated buildings separate into two groups, corresponding to wide and narrow separation, but are mixed together for the sheltered building. This foreshadows the important role of aperture separation in the next section.

The result (8) provides the starting point for the final stage in the model development: to predict the nondimensional flow rate in terms of wind and building parameters. This requires the intermediate step of developing relations between the pressure coefficients, $\Delta \square_{\square}$ and $\square_{\Delta \square_{\square}}$, and these parameters. This analysis is described in the next section. 


\section{A simplified model for SS2}

In most building design situations, the pressure data needed to predict $\square^{\prime}$ using (8) are not available. For some of the simpler isolated building geometries the static pressure component may be available but the unsteady component is not. Therefore, out of practical necessity, $\Delta \square_{\square}$ and $\square_{\Delta \square}$ need to be re-expressed in terms of accessible independent parameters, such as opening separation and incoming wind angle. Further, we expect that the resultant simplified model will clearly display and quantify the impact of aperture separation in SS2 flows.

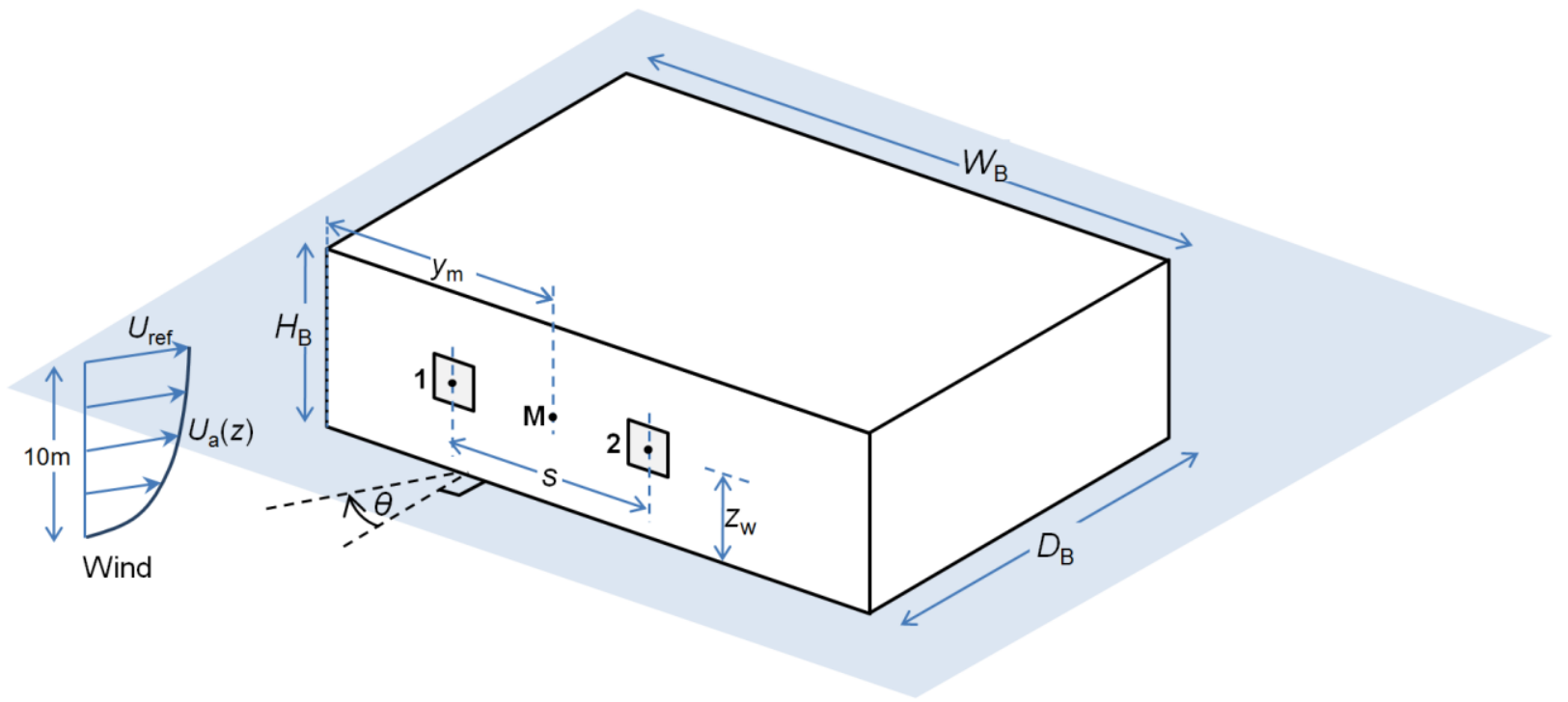

Figure 10: SS2 model configuration.

The first step in building a simplified model is to choose the independent modelling parameters that will be used. Figure 10 shows the reference geometry that will be used, along with the nomenclature. The centres of the two SS2 openings are separated horizontally by a distance $s$, and are located at a height $z_{\mathrm{w}}$ above the ground. The openings are taken to be of the same area, $A$, and are at the same vertical level $z_{\mathrm{w}}$. The mid-point between the openings, $\mathbf{M}$, is a horizontal distance $y_{\mathrm{m}}$ from the building edge. The incoming wind, whose magnitude upstream is $U_{\text {ref }}$ at reference height $z_{\text {ref }}=10 \mathrm{~m}$, approaches from a direction making an angle $\theta$ with the normal to the openings façade such that $|\theta| \leq 180^{\circ}$. Since the openings for SS2 are typically at the same height, in practice we will consider only pairs of points with the same vertical coordinate $z_{\mathrm{w}}$. Further, we introduce two additional groups of parameters: geometry characteristics for building $(\boldsymbol{B})$ and site $(\boldsymbol{S})$. 
The non-dimensional quantities that will be used throughout the analysis, and which are denoted with a prime, e.g. $\square^{\prime}$, are defined as follows:

Horizontal lengths: $\square^{\prime}=\square / \square_{\square}, \square_{\square}^{\prime}=\square_{\square} / \square_{\square}$

Vertical lengths: $\square_{\square}^{\prime}=\square_{\square} / \square_{\square}$

Note that the wind velocity has already been scaled out of the problem through the use of pressure coefficients. Further, the opening areas do not appear in this part of the model since we seek to predict pressure differences, which are not affected by building opening area. As a modelling approximation we divide the parameters into primary, and secondary:

\section{Primary: $\square, \square^{\prime}, \square_{\square}^{\prime}$}

Secondary: $\square_{\square}^{\prime}, \boldsymbol{B}, \boldsymbol{S}$

We investigated the dependence of the predicted pressure differences on the secondary parameters and concluded that although there is an effect, the available data are insufficient for a systematic study of their impact and, therefore, we choose to include only primary parameters in the models. As a result, $\Delta \square_{\square}$ and $\square_{\Delta \square}$ will only depend on the primary non-dimensional parameters, as follows

$$
\begin{aligned}
& \Delta \square_{\square}=\square\left(\square, \square^{\prime}, \square_{\square}^{\prime}\right) \\
& \square_{\Delta \square_{\square}}=\square\left(\square, \square^{\prime}, \square_{\square}^{\prime}\right)
\end{aligned}
$$

for some functions $F$ and $G$.

In order to define these functions, we used the pressure data for the long 'South' façade, shown schematically in the top-left portion of Figure 11, for two main reasons. First, this façade is pertinent to the ventilation runs; and second, it also offers the richest source of pressure difference data - there are 18 pressure sensors along the façade at the same vertical height (mid-window height), indicated by dots in the figure, and there is one test for each of the 17 wind angles. Thus $\Delta p$ computed for pairs of sensors will correspond to a wide range of values of $\square^{\prime}$ and $\square_{\square}^{\prime}$, with good resolution in the wind angle $\theta$. Analysis of these data allowed the forms for the functions $F$ and $G$ to be deduced. The procedure, described in 
Section 3.1, was repeated for the 3 building/room/environment cases, and the results pooled into the final modelling expressions. Different approaches were used for the mean and fluctuating parts.

Once $F$ and $G$ have been established, it is necessary to calculate new correlation constants $a_{\mathrm{p}}$ and $a_{\sigma}$ in (7) by matching the predicted ventilation rate, based now on the "synthetic" ventilation coefficients (9) and (10), with the data from the wind tunnel tests.

\subsection{A simplified model for mean pressure difference}

Analysis of the available surface pressure data showed that the mean pressure distribution along the façade at each wind angle is sufficiently smooth to allow an interpolation curve $\square$ ( $\square$ ) to be accurately fitted to the data using a 4th-order polynomial. This allowed us to go beyond simply using the sensor positions and enabled static pressure values at any two points along the façade to be used in computing $\Delta \square_{\square}$, resulting in a continuous map of $\Delta \square_{\square}\left(\square^{\prime}, \square_{\square}^{\prime}\right)$ for each set of wind and external parameters. This approach is possible because $\Delta \square_{\square}$ depends linearly on the pressure difference.

Figure 11 presents an example of the interpolation process for the 2-storey isolated building, shown schematically above the graph, and an incoming wind angle of $\theta=45^{\circ}$ (so that the façade is on the windward side of the building, and pressures are all positive). Each point on the left-hand graph is the time-averaged pressure at that sensor. For this case, the fourth-order polynomial used to fit the data has a Pearson correlation coefficient $r=0.991$. The lines shown on the right-hand side of the figure were obtained by selecting pairs of points such that, for a given separation $\square^{\prime}$, which is varied between 0.05 and 0.85 , the midpoint of the pair $\square_{\square}^{\prime}$ is varied continuously over the range $\square^{\prime} / 2 \leq \square_{\square}^{\prime} \leq 1-\square^{\prime} / 2$. The resulting curves form a map $\Delta \square_{\square}\left(\square^{\prime}, \square_{\square}^{\prime} ; \square\right)$, and are plotted in the right-hand graph in Figure 11. The map was generated for all 17 wind angles for the 2-storey isolated building, and then the whole process repeated for the other two scenarios, 4B-Iso and 2-LowWide. Note that the lines on the right-hand side have variable horizontal extent because increased separation narrows the range of geometrically possible mid-point positions. 

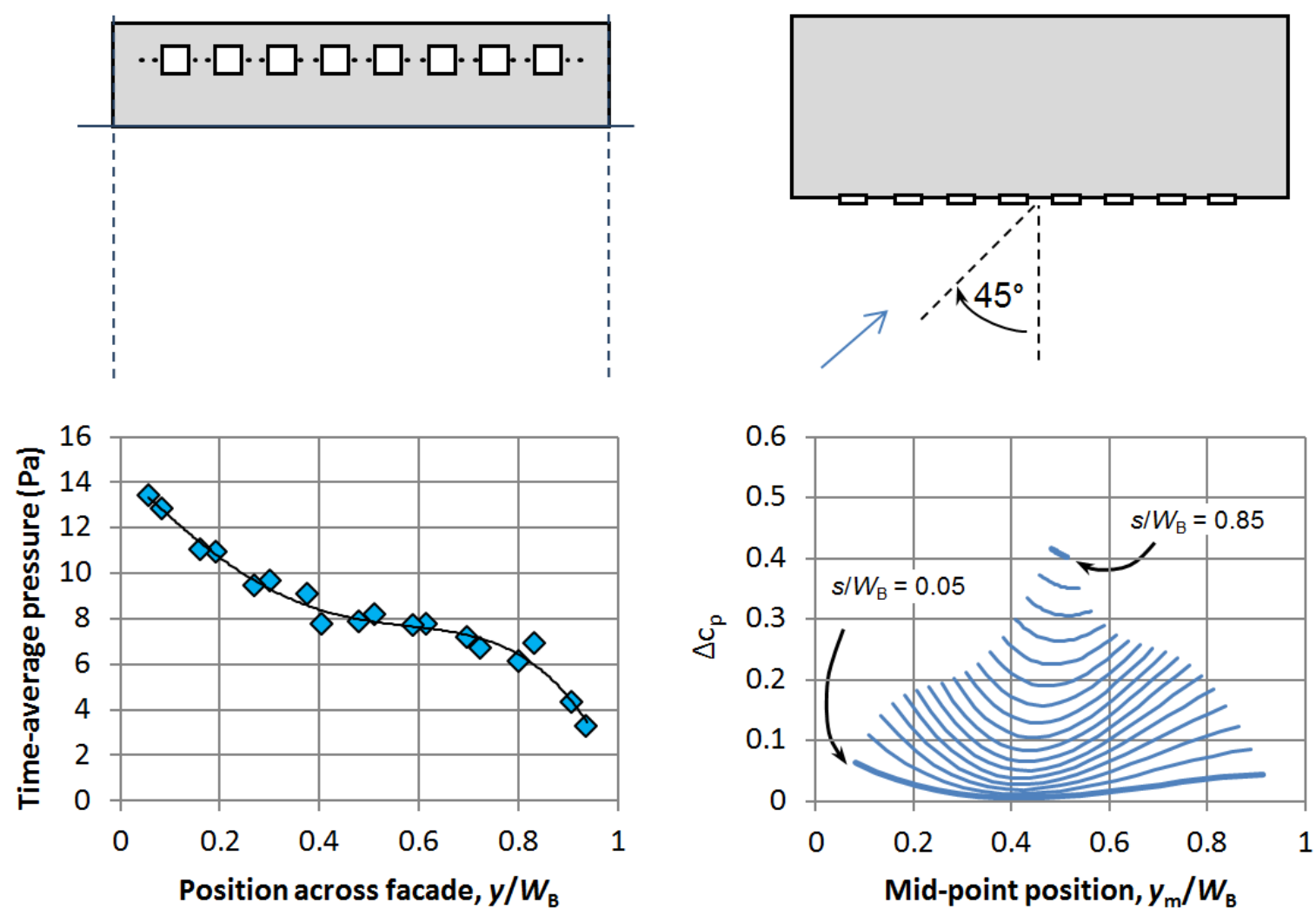

Figure 11: Left: mean pressure profile along façade 2-storey isolated building, $\theta=45^{\circ}$. Right: mean pressure difference as function of mid-point position.

Analysis of Figure 11 reveals that the lines of constant separation $\square^{\prime}$ are relatively horizontal, i.e. $\Delta \square \square$ depends primarily on the separation of the openings $\square^{\prime}$ and only weakly on the position, $\square_{\square}^{\prime}$, of the openings along the façade for a given separation. As the wind angle is varied this pattern is repeated. The main exception to this is near $\theta=90^{\circ}$, for which there are strong gradients in mean pressure near the edges, introducing a more marked dependence on the location of the openings when either is near an edge.

These results suggest simplifying the data by averaging each curve $\square^{\prime}=$ constant over $\square_{\square}^{\prime}$ to give $\overline{\Delta \square_{\square}}(\square, \square)$, where here the overbar denotes the average with respect to $\square_{\square}^{\prime}$. This simplification process removes the variable $\square_{\square}^{\prime}$ from the model, at the expense of increased modelling error. The result of this process is plotted in Figure 12(a) for the 2-storey isolated building, plotted as a series of curves $\square^{\prime}=$ constant (the values of $\square^{\prime}$ are $0.05,0.15, \ldots, 0.85$ ). The red dots denote the points that would be obtained from averaging the corresponding curves shown on the right-hand side of Figure 11. 


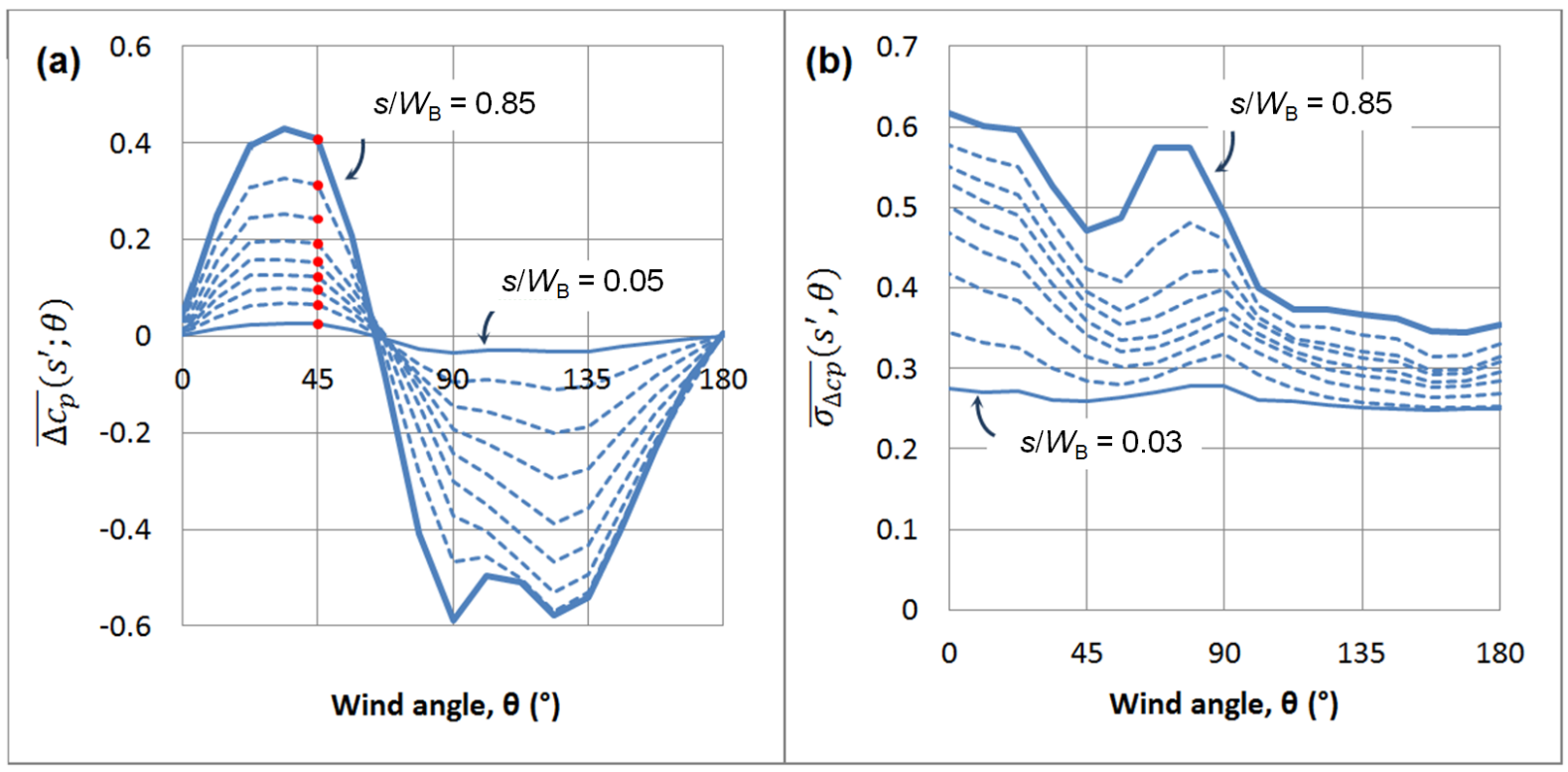

Figure 12: Pressure difference for 2-storey isolated building: (a) mean and (b) unsteady parts.

Figure 12 shows that, for a given angle there is an approximately linear increase in $\overline{\Delta \square_{\square}}$ with separation (since the curves are at equal increments of $\square^{\prime}$ ), which further suggests modelling these curves according to the formula (dropping the overbar)

$$
\Delta \square_{\square}\left(\square^{\prime}, \square\right)=\square^{\prime} \cdot \Pi(\square)
$$

for some universal shape function $\Pi(\theta)$. The graphs suggest an approximation function with a piecewisesinusoidal form

$$
\Pi(\square)=\left\{\begin{array}{cc}
\square_{1} \sin \left[\frac{\square}{\square_{0}} \cdot 180\right] & \square \leq \square_{0} \\
-\square_{2} \sin \left[\frac{\left(\square-\square_{0}\right)}{\left(180-\square_{0}\right)} \cdot 180\right] & \square_{0} \leq \square \leq 180^{\circ}
\end{array}\right.
$$

for adjustable constants $C_{1}$ and $C_{2}$ and $\theta_{0}=67.5^{\circ}$. By optimizing the least-squares fit of this formula to the points in Figure 12(a) (plus those in the corresponding curves for the other two scenarios), values of 0.44 and 0.69 were found for $C_{1}$ and $C_{2}$, respectively. Substituting these into (11) and (12), and generalizing the result to negative wind angles, we obtain a formula for the mean pressure difference between the two openings:

$$
\Delta \square_{\square}=\left\{\begin{array}{cc}
0.44 \operatorname{sgn}(\square) \sin (2.67|\square|) \cdot \square & |\square| \leq \square_{0} \\
-0.69 \operatorname{sgn}(\square) \sin (288-1.6|\square|) \cdot \square^{\prime} & \square_{0} \leq|\square| \leq 180^{\circ}
\end{array}\right.
$$




$$
\square_{0}=67.5^{\circ}
$$

\subsection{A simplified model for unsteady pressure difference}

An analogous procedure was followed to model the unsteady part of the pressure difference, $\square_{\Delta \square_{\square}}$, i.e. determine the standard deviation of the pressure difference at any two locations along the façade, average over the mid-point location and repeat for each wind direction and building scenario. The main difference compared with the approach used in the previous section is that it is no longer possible to use an interpolation curve to fit the data (as in Figure 11, left) since $\square_{\Delta \square} \neq \square_{\square 1}-\square_{\square 2}$. Thus, instead, all possible pairs of points were considered to generate a finite set of values $\left\{\square_{\Delta \square \square}\left(\square_{\square}, \square_{\square, \square} ; \square\right)\right\}$ for each wind direction and building scenario. Because of the regular arrangement of sensors along the façade, these values could be grouped into sets with closely-matched separations but different mid-point coordinates, thereby obtaining a discrete map of $\square_{\Delta \square \square}$ variation (rather than the continuous map obtained for $\Delta \square_{\square}$ ). The $y_{\mathrm{m}^{-}}$ averaged curves of $\square_{\Delta \square \square}$ for the 2-storey isolated building are shown in Figure 12(b) (the values of $\square$ ' are $0.03,0.11,0.21,0.32,0.43,0.53,0.64,0.75,0.85)$. Just as in the case of the mean pressure difference, there is a monotonic increase in $\square_{\Delta \square}$ with separation, broadly linear, and here superimposed on a minimum value, suggesting the following representation of these curves

$$
\square_{\Delta \square \square}\left(\square^{\prime}, \square\right)=\Sigma_{0}+\square^{\prime} \cdot \Sigma(\square)
$$

for another "universal" shape function $\Sigma(\theta)$ and minimum value $\Sigma_{0}$ (again dropping the overbar). Each curve $\square^{\prime}=$ constant in Figure 12(b) is approximated by a straight line, whose slope varies between zero and a maximum value for the widest separation $\square_{\square \square \square}^{\prime}=0.85$ (see Figure 13)

$$
\Sigma(\square)=\frac{1}{\square_{\square \square \square}^{\prime}}\left[\frac{\left(\square_{2}-\square_{1}\right)}{180} \square+\square_{1}\right]
$$

where $\delta_{1}$ and $\delta_{2}$ are adjustable constants that best fit the experimental data when $\delta_{1}=0.36, \delta_{2}=0.11$ and $\Sigma_{0}=0.24$ 


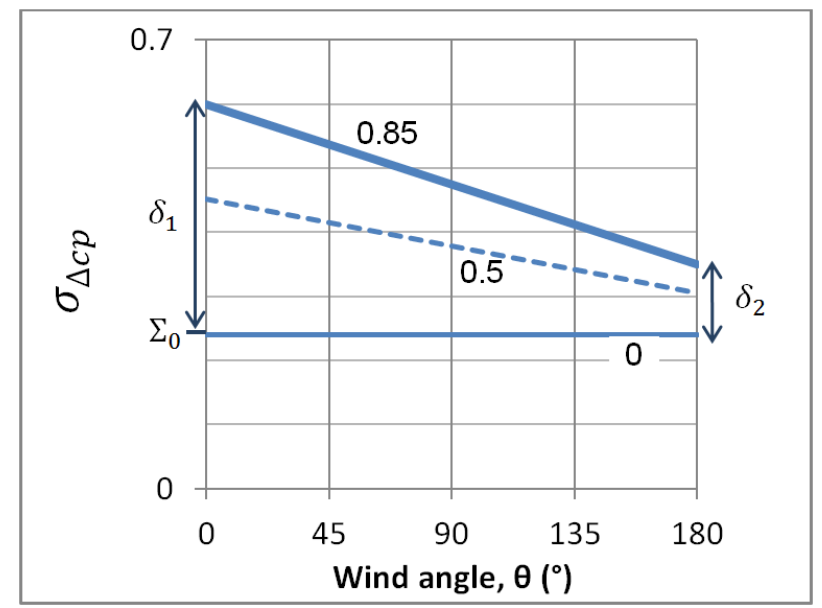

Figure 13: Linear approximation to unsteady pressure difference curves.

The resulting formula for $\square_{\Delta \square \square}$ is then

$$
\square_{\Delta \square_{\square}}=0.24+\left(0.423-1.63 \times 10^{-3}|\square|\right) \cdot
$$

Figure 14 shows an example of $\Delta \square_{\square}$ and $\square_{\Delta \square_{\square}}$ generated by (13)/(14) and (17), respectively, compared with the data for the 2-storey isolated building and wide opening separation.
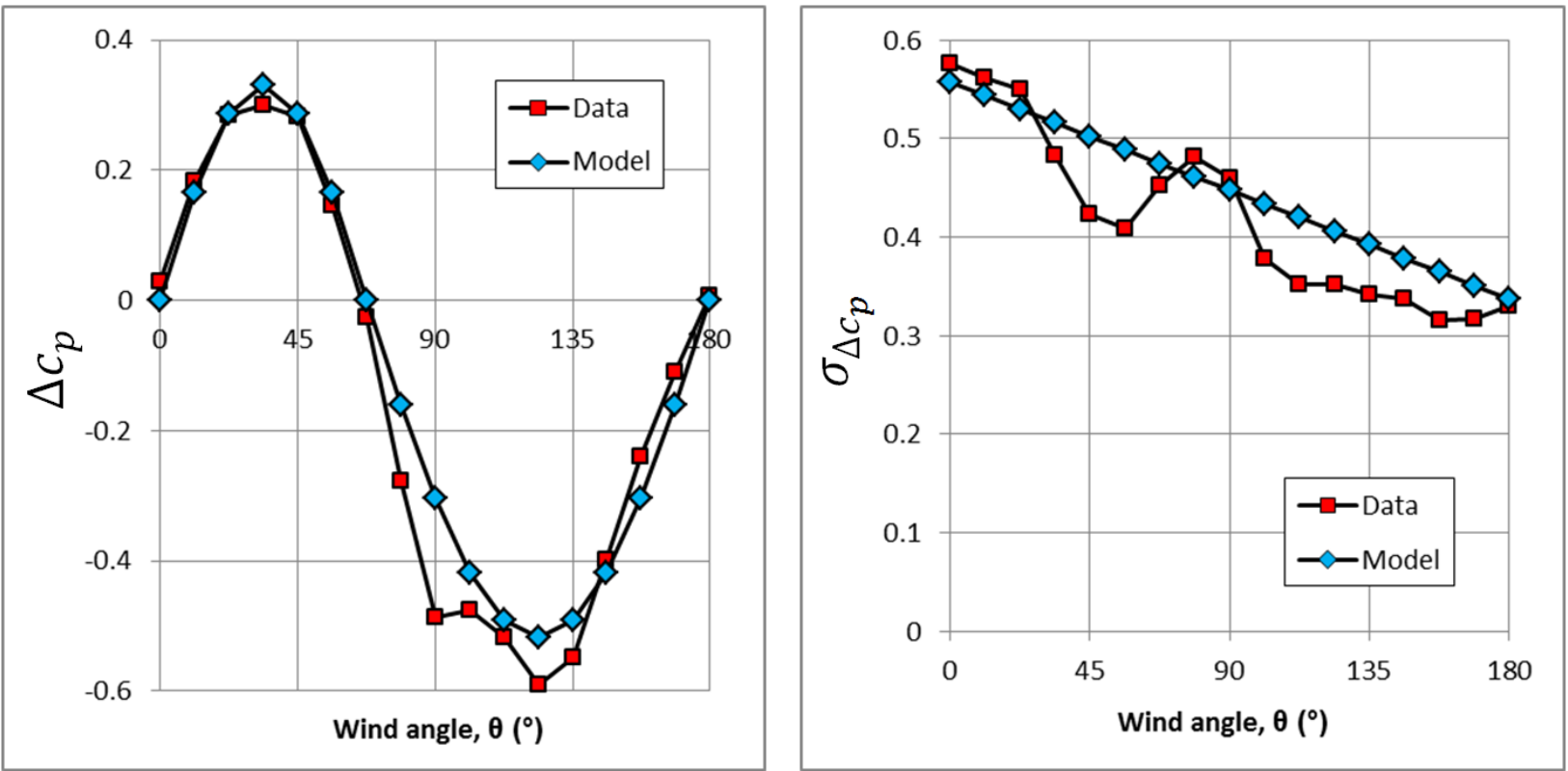

Figure 14: Example comparison of model and data for mean (left) and unsteady (right) pressure difference coefficients. 
Having approximated the two pressure coefficient terms in (7) in terms of the dimensionless opening separation and the relative wind angle, it is necessary to re-calculate the optimum values of the coefficients $a_{\mathrm{p}}$ and $a_{\sigma}$. The best fit occurs with $a_{\mathrm{p}}=0.343$ and $a_{\sigma}=0.084$, and combining with the previous results the final correlation formula for the non-dimensional flow rate $\square$ 'is therefore

$$
\frac{\square}{\square_{\square \square \square} \square_{\square}\left(\square_{\square \square \square}\right)}=\square^{\prime}=\sqrt{0.02+[0.343|\Pi(\square)|+0.084 \Sigma(\square)] \cdot \square^{\prime}}
$$

This is the parameter-based counterpart to the data-based formula (8).

Analysis of this expression reveals that:

- When the separation is small ( 0.05), an increment in separation can have a significant effect on flow rate: for example, increasing the separation by 0.1 results in an increase in the flow rate of up to one-third.

- In contrast, when the separation is large $(\sim 0.5)$ a similar increment $(0.1)$ leads to a much smaller increase in flow (typically 7\%).

- For incoming winds such that $|\theta|<67.5^{\circ}$ both pressure components contribute to the flow, but to a varying degree depending on the wind angle: for nearly head-on winds $(|\theta|$ small) the flow is driven mostly by the fluctuating part while for $|\theta| \sim 30^{\circ}$, it is mostly the mean pressure difference that drives the flow (c.f. Chu et al., [18], discussed in the Introduction).

- For incoming winds such that $70^{\circ}<|\theta|<170^{\circ}$ mean pressure difference dominates the flow. This aligns with the observations of these flows (Section 1), in which there is a clear preferred inflow opening for wind angles in much of this range.

- When $|\theta|$ approaches $180^{\circ}$ the flow is driven by the fluctuating pumping mechanism described in Section 2.1.

shows the correlation between the measured and predicted flow rates. Again, the data points have been split into three groups, corresponding to the three building configurations. Comparison with Figure 8 confirms that overall the proposed model has comparable precision to a modelling approach based explicitly on pressures, with the same general trend in accuracy from left to right: thus, the same advisory applies to use of 
the results as that given in the discussion of the pressure-based formula. Note that the 2-storey sheltered case shows greater scatter compared with the pressure-based result: this is likely a reflection of the fact that data for a (2-storey) isolated building was used to derive the shape functions $\Pi(\square)$ and $\Sigma(\square)$ in Equations (11) and (15), respectively.
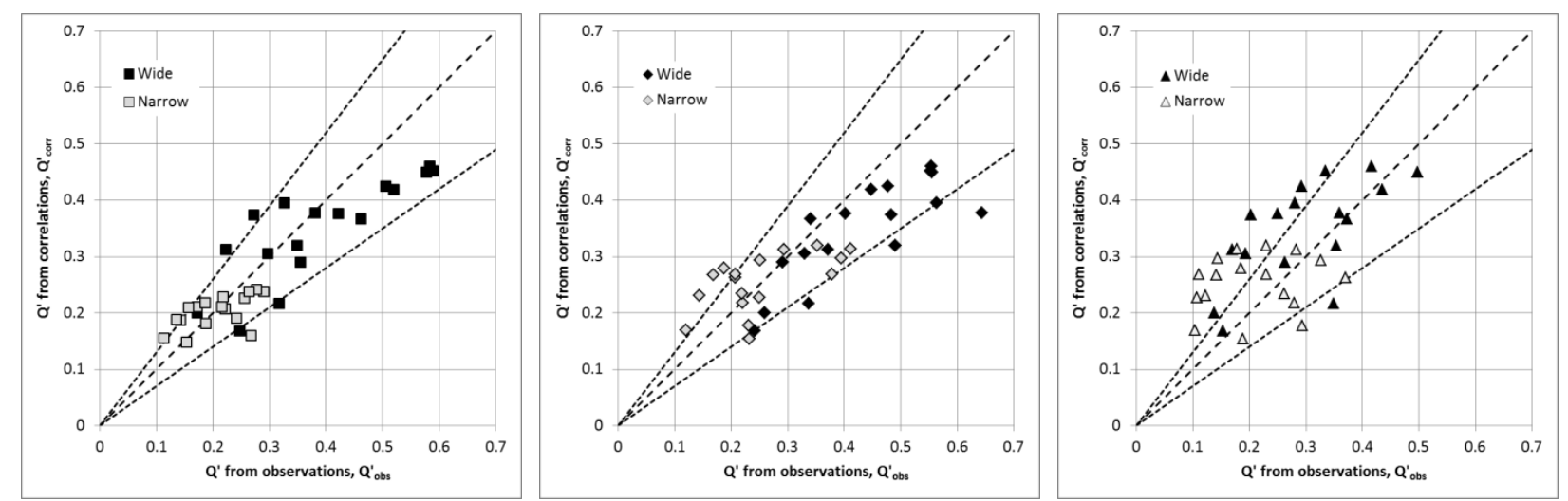

Figure 15: Comparison of parameter-based ventilation rate formula (18) with data.

The three charts plot subsets of the data corresponding to the 2-storey isolated (left), 4-storey isolated (centre) and 2-storey sheltered (right) buildings. In each case, results for the two aperture separations are distinguished and the upper and lower dashed lines indicate $\pm 30 \%$ errors.

\subsection{Capabilities and limitations of the proposed model}

The range of application of the model is easier to establish by considering three different scales:

- At the urban scale the model is applicable to an isolated building or a building that is surrounded by smaller buildings or a low rise building surrounded by similar buildings, with highest confidence for isolated buildings. The model should not be applicable to high rise buildings surrounded by similar high rises.

- At the building scale the model is applicable to rectangular buildings with openings in the widest face (the most common opening position). The model is not applicable to predict ventilation due to openings in the shorter edge of rectangular buildings.

- At the room scale the model is applicable to two openings at equal height with similar areas. The model was not tested for cases when $A_{1}$ is different from $A_{2}$ : it is likely that when, say, $\square_{2} \gtrsim 2 \square_{1}$ the modelling precision will be reduced. 


\section{Conclusions}

This paper presents a study of SS2 flows based on wind tunnel measurements and dimensional analysis. A two-level approach to modelling the flow rate is developed: either pressure-based, in the event that surface pressure data are available for the configuration, or parameter-based, when such pressure data are unavailable. The parameter-based results show that the SS2 ventilation flow rate depends on the incoming wind velocity and angle and on the aperture separation scaled by building width, $\square$ '. For most wind angles there is a square-root increase in ventilation flow with aperture separation. This dependence implies that when the separation is low $\left(\square^{\prime} \sim 0.1\right)$ there is significant benefit from increasing the separation. Once the separation is large $\left(\square^{\prime}>1 / 2\right)$ the benefits from increased separation are very limited. The largest SS2 flows occur for large aperture separation $\left(\square^{\prime}>1 / 2\right)$. Since typical rooms ventilated by SS2 systems have 3-9m width, large values of $\square^{\prime}$ can only be achieved for narrow buildings whose width does not exceed $\sim 20 \mathrm{~m}$. SS2 rooms in large office towers always have small relative aperture separation. For these cases the wind driven single sided flow is similar to SS1 and therefore up to five times weaker than the strongest SS2 flows that occur in smaller buildings.

Finally, this study also identified a novel flow driving mechanism: vortex shedding. When the ventilation openings are on the leeward side of the building and the wind is nearly head-on $\left(|\square| \gtrsim 175^{\circ}\right)$ the flow is driven by a pumping mechanism due to vortex shedding. In these cases the flow direction alternates at a mean rate close to the Strouhal frequency.

\section{Acknowledgements}

The authors gratefully acknowledge the contribution of staff at CPP Wind Engineering, Inc., for running the wind tunnel tests that produced the data used to develop our model; and financial support for one of us (GCG) from Instituto Dom Luiz (UID/GEO/50019/2013).

The work described in this paper was carried out under California Energy Commission contract 500-10-025, and their financial support is gratefully acknowledged. 


\section{References}

[1] Martins, N.R. and Carrilho da Graça, G. (2016) Validation of numerical simulation tools for wind-driven natural ventilation design. Build. Simul. 9(1), 75-87. DOI: 10.1007/s12273-015-0251-6

[2] Karava, P., Stathopoulos, T. and Athienitis, A.K. (2011) Airflow assessment in cross-ventilated buildings with operable façade elements, Building and Environment 46(1), 266-279. DOI: 10.1016/j.buildenv.2010.07.022

[3] Carrilho da Graça, G., Linden, P.F. and Haves, P. (2004) Design and testing of a control strategy for a large, naturally ventilated office building. Building Serv. Eng. Res. Technol. 25(3), 223-239. DOI:

$10.1191 / 0143624404$ bt107oa

[4] Chu, C.R., Chiu, Y.-H., Chen, Y.-J., Wang, Y.-W. and Chou, C.-P. (2009) Turbulence effects on the discharge coefficient and mean flow rate of wind-driven cross-ventilation. Building and Environment 44(10), 2064-2072. DOI: 10.1016/j.buildenv.2009.02. 012

[5] Linden, P., Adams, K., Arens, E., Banks, D., Brunswick, S., Carrilho da Graca, G., Daish, N., Dutton, S., Fisk, W., Fountain, M., Gerard, R., Gillan, F., Gross, G., Haves, P., Hill, M., Honnekeri, A., Hovanec, M., Lawton, T., Pigman, M., Switenki, P., Szakats, G., Thomas, R., Zhai, Y. and Zhang, H. (2014) Natural ventilation for energy savings in California commercial buildings. Draft Final Report to California Energy Commission, Contract 500-10-025. See http://www.escholarship.org/uc/item/4cd386s7

[6] Carrilho da Graça, G., Daish, N.C. and Linden, P.F. (2015) A two-zone model for natural cross-ventilation. Building and Environment 89, 72-85. DOI: 10.1016/j.buildenv.2015.02.014

[7] Carrilho da Graça, G. and Linden, P.F. (2016) Ten questions about natural ventilation of non-domestic buildings. Submitted to Building and Environment.

[8] Warren, P.R. and L.M. Parkins (1986) Single-sided ventilation through open windows. In Thermal performance of the exterior envelopes of buildings III: proceedings of the ASHRAE/DOE/BTECC conference, December 2-5, 1985, Holiday Inn Surfside Hotel, Clearwater Beach, Florida, pp. 209-228. ISBN: 091011045X (pbk.)

[9] Larsen, T.S. and Heiselberg, P. (2008) Single-sided natural ventilation driven by wind pressure and temperature difference. Energy and Buildings 40(6), 1031-1040. DOI: 10.1016/j.enbuild.2006.07.012

[10] Kato, S., Kono, R., Hasama, T., Ooka, R. and Takahashi, T. (2006) A wind tunnel experimental analysis of the ventilation characteristics of a room with single-sided opening in uniform flow. International Journal of Ventilation 5(1), 171-178. DOI: 10.1080/14733315.2006.11683734

[11] Yamanaka, T., Kotani, H., Iwamoto, K. and Kato, M. (2006) Natural, wind-forced ventilation caused by turbulence in a room with a single opening. International Journal of Ventilation 5(1), 179-187. DOI:

$10.1080 / 14733315.2006 .11683735$

[12] Ai, Z.T. and Mak, C.M. (2014) Analysis of fluctuating characteristics of wind-induced airflow through a single opening using LES modeling and the tracer gas technique. Building and Environment 80, 249-258. DOI:

10.1016/j.buildenv.2014.06.002

[13]Heiselberg, P., Bjørn, E. and Nielsen, P.V. (2002) Impact of open windows on room air flow and thermal comfort. International Journal of Ventilation 1(2), 91-100.

[14] Caciolo, M., Stabat, P. and Marchio, D. (2011) Full scale experimental study of single-sided ventilation: Analysis of stack and wind effects. Energy and Buildings 43(7), 1765-1773. DOI: 10.1016/j.enbuild.2011.03.019.

[15] Wang, H., Karava, P. and Chen, Q. (2015) Development of simple semiempirical models for calculating airflow through hopper, awning, and casement windows for single-sided natural ventilation. Energy and Buildings 96, 373-384. DOI: 10.1016/j.enbuild.2015.03.041 
[16] Cóstola, D., Blocken, B., Ohba, M. and Hensen, J.L.M. (2010) Uncertainty in airflow rate calculations due to the use of surface-averaged pressure coefficients. Energy and Buildings 42(6), 881-888. DOI:

10.1016/j.enbuild.2009.12.010

[17] Teppner, R., Langensteiner, B., Meile, W., Brenn, G. and Kerschbaumer, S. (2014) Air change rates driven by the flow around and through a building storey with fully open or tilted windows: An experimental and numerical study. Energy and Buildings, 80, 570-583. DOI: 10.1016/j.enbuild.2014.07.020

[18] Chu, C.-R., Chiu, Y.-H., Tsai, Y.-T. and Wu, S.-L. (2015) Wind-driven natural ventilation for buildings with two openings on the same external wall. Energy and Buildings 108, 365-372.DOI: 10.1016/j.enbuild.2015.09.041

[19] Strouhal, V. (1878) Ueber eine besondere Art der Tonerregung. Ann. Phys. 214, 216-251. DOI:

10.1002/andp.18782411005

[20] Crawley, D.B., Lawrie, L.K., Winkelmann, F.C., Buhl, W.F., Huang, Y.J., Pedersen, C.O., Strand, R.K., Liesen, R.J., Fisher, D.E., Witte, M.J. and Glazer, J. (2001) EnergyPlus: creating a new-generation building energy simulation program. Energy and Buildings 33(4), 319-331. DOI: 10.1016/S0378-7788(00)00114-6

[21] Richards, P.J. and Norris, S.E. (2011) Appropriate boundary conditions for computational wind engineering models revisited. J. Wind Eng. Ind. Aerodyn. 99(4), 257 266. DOI: 10.1016/j.jweia.2010.12.008

[22] Snyder, W.H. (1981) Guideline for fluid modeling of atmospheric diffusion. U.S. Environmental Protection Agency Publication No. EPA-600/8-81-009. 185pp.

[23] Cermak, J.E. (1971) Laboratory simulation of the atmospheric boundary layer. AIAA Journal 9(9), $1746-1754$.

DOI: $10.2514 / 3.49977$

[24] Cermak, J.E. (1975) Applications of fluid mechanics to wind engineering - a Freeman Scholar lecture. J. Fluids Eng. 97(1), 9-38. DOI: 10.1115/1.3447225

[25] Cermak, J.E. (1976) Aerodynamics of buildings. Ann. Rev. Fluid Mech. 8, 75-106. DOI:

10.1146/annurev.fl.08.010176.000451

[26] Etheridge, D.W. and Sandberg, M. (1996) Building ventilation: theory and measurement. John Wiley \& Sons. 754pp. ISBN-13: 978-0471960874 